\title{
Prediction and modeling of fluoride concentrations in groundwater resources using an artificial neural network: a case study in Khaf
}

\author{
Ali Akbar Mohammadi ${ }^{1}$, Mansour Ghaderpoori ${ }^{2}$, Mahmood Yousefi $^{3}$, Malihe Rahmatipoor ${ }^{3}$, Safoora Javan $^{4}$ \\ ${ }^{1}$ Lecturer, Department of Environmental Health Engineering, Neyshabur University of Medical Sciences, Neyshabur, Iran \\ ${ }^{2}$ Assistant Professor, Department of Environmental Health Engineering, Faculty of Health and Nutrition, Lorestan University of \\ Medical Sciences, Khorramabad, Iran \\ ${ }^{3}$ B.S., Students Research Committee, Neyshabur University of Medical Sciences, Neyshabur, Iran. \\ ${ }^{4}$ M.S., Students Research Committee, Department of Environmental Health Engineering, Neyshabur University of Medical Sciences, \\ Neyshabur, Iran
}

\begin{abstract}
Background: One issue of concern in water supply is the quality of water. Measuring the qualitative parameters of water is time-consuming and costly. Predicting these parameters using various models leads to a reduction in related expenses and the presentation of overall and comprehensive statistics for water resource management.

Methods: The present study used an artificial neural network (ANN) to simulate fluoride concentrations in groundwater resources in Khaf and surrounding villages based on the physical and chemical properties of the water. ANN modeling was applied with regard to diverse inputs.

Results: The MLP 1 model with eight inputs of parameters such as root mean square error (RMSE) and correlation coefficient of actual and predicted outputs exhibited the best results. The lowest fluoride concentration $\left(0.15 \mathrm{mg} \mathrm{L}^{-1}\right)$ was found in Sad village, and the highest concentration $\left(3.59 \mathrm{mg} \mathrm{L}^{-1}\right)$ was found in Mahabad village. Based on World Health Organization (WHO) standards, 56.6\% of the villages are in the desirable range, $33.3 \%$ of them had fluoride concentrations below standard levels, and $10 \%$ had higher than standard concentrations of fluoride.

Conclusion: The simulation results from the testing stage for $\mathrm{MLP}_{1}$ as well as the high conformity between experimental and predicted data indicated that this model with its high confidence coefficient can be used to predict fluoride concentrations in groundwater resources.

Keywords: Water quality, Artificial neural network model, Fluoride, Groundwater

Citation: Mohammadi AA, Ghaderpoori M, Yousefi M, Rahmatipoor M, Javan S. Prediction and modeling of fluoride concentrations in groundwater resources using an artificial neural network: a case study in Khaf. Environmental Health Engineering and Management Journal 2016; 3(4): 217-224. doi: 10.15171/EHEM.2016.23
\end{abstract}

\section{Article History:}

Received: 9 August 2016

Accepted: 26 October 2016

ePublished: 1 November 2016

\section{Introduction}

The provision of qualified drinking water is a noteworthy issue in today's world. One of the qualitative factors considered in water is fluoride (1-3). Fluoride is one of the fourteen elements necessary for human life and affecting growth and fertility (4). After entering the body, fluoride rapidly rushes into extracellular and intracellular fluid, and its surplus concentration is stored in bones and teeth or excreted in urine (5). It has long been known that the addition of fluoride to water equal to one milligram per liter and to toothpaste reduces tooth decay by $20 \%$ (5). The World Health Organization (WHO) recommends that the appropriate fluoride concentration to be added to water is between 0.5 and $1 \mathrm{mg} \mathrm{L}^{-1}(6)$. Concentrations greater than $7.1 \mathrm{mg} \mathrm{L}^{-1}$ cause fluorosis, and concentrations higher than 3-6 mg L $\mathrm{m}^{-1}$ cause bone problems (7). Excessive intake of fluoride causes such complications as gastrointestinal disorders, loss of teeth in young adults, increase in hip fractures in aged people, immune system disorders, learning disorders, and low-IQ (8).

Computer models are useful tools for water resource management (9). Such models were established for use in monitoring and managing water resources $(10,11)$, and their use can be of great help to the quality management of groundwater resources (12). Increasing the development of computational approaches such as artificial intelligence and using artificial neural networks inspired by the human brain structure have been widely applied in studies related 
to predicting the diverse parameters of water resources. Researchers have approved the high precision of these methods compared with experimental and regression methods $(13,14)$. These models are very attractive because of their ability to solve nonlinear, too parallel, voluminous, and erroneous problems. Moreover, they have the ability to solve phase problems and recognize patterns (15).

The artificial neural network (ANN) was proposed for the first time by McCulloch and Pitts; it was then completed by other investigators (16). ANN is the simulation of a natural neural network that includes a set of neural units known as a neuron which is connected by a series of connections known as axons. ANN tries to design a structure similar to the biological structure of the human brain and nervous system so that it can have the same power of learning, generalization, and decision-making (17).

Among the studies conducted in the area of applying ANNs in problems such as water quality, noteworthy is the study by Hore et al on the application of a neural network to estimate the affective parameters of water pollution in the Tolly channel in India (18). Huiqun and Ling conducted a study in China and examined the quality of Chung Dong river water by an ANN and fuzzy logic (19). Kunwar et al used a perceptron neural network in modeling the qualitative parameters of Gomti in India and benefited from its efficiency (20). Sandhu and Finch also approved the ANN's ability to make daily and real predictions of different levels of salt in water basins as well as its ability to estimate concentrations of cation and anion and amounts of EC and TDS in these basins (21). Walley and Fontana conducted a study in England to examine the water quality of rivers in Britain using an ANN based on the back propagation algorithm and found a precision of 95.62\% (22).

The aims of the current study were to use an ANN to predict fluoride concentrations in water resources and to attempt to establish the multilayer structure of a perceptron neural network for modeling fluoride by certain physical and chemical parameters of water. The neural network learning opportunities for parametric modeling of fluoride using qualitative parameters of water were also evaluated.

\section{Methods}

Studied region

Khaf is a city in Khorasan Razavi province and is located at 59528 to 60556 longitude and 33540 to 35505 latitude. It has an area of $9797 \mathrm{~km}^{2}$ and a population of more than 100000 people. The city also shares a border of about 120 $\mathrm{km}$ with Afghanistan (23). The study area is shown in Figure 1. Data from Khaf's meteorological station showed that in the 7-year period from 2006 to 2012, the average rainfall was $123.6 \mathrm{~mm}$.

\section{Methodology}

This work was a descriptive cross-sectional study. Sampling was implemented during 2009-2010. In this



Figure 1. Study area of Khaf city.

study, 6 samples were collected from each of 30 water sources examined $(30 \times 6=180)$. Of the 180 samples, 4 were excluded due to non-standard conditions during transport to the laboratory. Finally, 176 samples were investigated. Samples were collected in polyethylene bottles and transported under standard conditions to the laboratory. Samples were taken in the two seasons of autumn (low rainfall) and spring (high rainfall). Fourteen parameters were analyzed. All sampling and data analyses were conducted based on the standard methods of water and wastewater management (24). Experiments were administered in 2 categories of machine and titrimetric experiments at the water and sanitation laboratory in Torbat-Heydariye.

\section{Artificial neural networks}

The ANN structure model in this study was composed of 3 distinct layers. Figure 2 shows the ANN structure. The input layer is introduced to the model by input layer data in which all input layers are weighted. The hidden layer or layers are where the data is processed, and the output layers produce results. Each layer is composed of one or more basic element named a "neuron" or "node". Each neuron has a threshold and an activity function, both of which are important to the training process (25). A singlelayer network is shown in Figure 3.

A perceptron layer is composed of $n_{1}$ units (an input



Figure 2. Artificial neural network structure. 


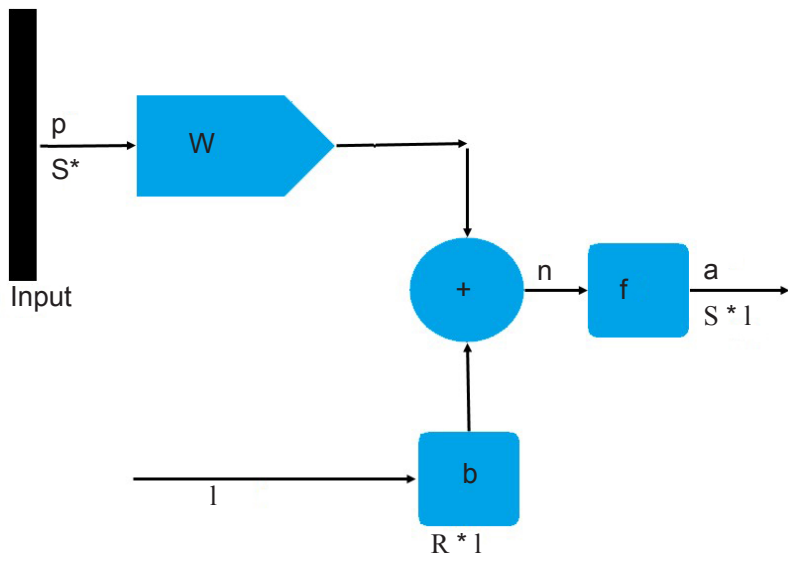

Figure 3. Single-layer perceptron neural network

layer), $n_{2}$ units (a hidden layer), and $n_{3}$ units (an output layer). Based on Figure 2, $\left(x_{3}, k, k=l, n_{3}\right)$ outputs are calculated according to Equations 1 and 2, as follows (20):

$$
\begin{aligned}
& \mathrm{x}_{2, \mathrm{j}}=\mathrm{f}\left(\sum_{\mathrm{i}=0}^{\mathrm{n}_{1}-1} \mathrm{w}_{2, i, j} \mathrm{x}_{1, \mathrm{i}}\right), \mathrm{j}=1, \mathrm{n}_{2-1} \\
& \mathrm{x}_{3, \mathrm{j}}=\mathrm{f}\left(\sum_{\mathrm{i}=0}^{\mathrm{n}_{2}-1} \mathrm{w}_{3, \mathrm{i}, \mathrm{j}} \mathrm{x}_{2, \mathrm{i}}\right), \mathrm{j}=1, \mathrm{n}_{3}
\end{aligned}
$$

When $x_{1,0}=0$, a constant value is always used to calculate the output of the hidden layer. $x_{1}\left(i=l, \mathrm{n}_{1}-1\right)$, and $x_{2, j}(j$ $\left.=l, \mathrm{n}_{2}-1\right)$ are the input and output of the hidden layer, respectively. $w_{2, \mathrm{ij}}\left(i=l, \mathrm{n}_{1-}{ }_{1} j=l, \mathrm{n}_{2}-1\right)$ are the weights of the output and hidden layers which are used in the calculation of the hidden layer output. Also, $w_{3, j, k}(i=l$, $\mathrm{n}_{2}-l=l, \mathrm{n}_{3}$ ) show the hidden and output weights that are used in calculating the output layer output. An example of the non-linear transfer function $[\mathrm{f}(\mathrm{y})]$ in this study is the sigmoid function defined according to Equation 3, as follows:

$$
\mathrm{f}(\mathrm{y})=\frac{1}{1+\mathrm{e}^{-\mathrm{ky}}}
$$

Where $k$ is the parameter of determinative of the $\mathrm{f}(\mathrm{y})$ reaction. In this analysis, $k$ is constant due to its incompatibility with the propagation algorithm. Input and output values should be normalized between 0 and 1. The mean squared error between the output data of $t_{p, k}$ network and desirable outputs of $x_{3, \mathrm{k}}$ are defined according to Equation 4 as follows:

$$
\mathrm{E}_{\mathrm{p}}=\frac{1}{2} \sum_{\mathrm{k}=1}^{\mathrm{n}}\left(\mathrm{t}_{\mathrm{p}, \mathrm{k}}-\mathrm{x}_{3, \mathrm{k}}\right)^{2}
$$

Weights (w) and threshold values (o) are balanced by error transmission from the output layer to the hidden layer and from the hidden layer to the input layer according to Equations 5 to 8 as follows:

$$
\begin{aligned}
& \delta_{3, k}=k x_{3, k}\left(l-x_{3, k}\right)\left(t_{p, k}-x_{3, k}\right): k=l, n_{3} \\
& \delta_{2, \mathrm{k}}=\mathrm{kx}_{3, \mathrm{k}}\left(1-\mathrm{x}_{3, \mathrm{k}}\right) \sum_{\mathrm{k}=1}^{\mathrm{n}} \delta_{3, \mathrm{k}} \mathrm{w}_{3, \mathrm{i}, \mathrm{k}}: \mathrm{j}=1, \mathrm{n}_{2}-1, \mathrm{k}=1, \mathrm{n}_{3}
\end{aligned}
$$

$$
\begin{aligned}
& \mathrm{w}_{3, \mathrm{j}, \mathrm{k}}^{(\mathrm{M}+\mathrm{l})}=\mathrm{w}_{3, \mathrm{j}, \mathrm{k}}^{(\mathrm{m})}+\eta \delta_{3, \mathrm{k}} \mathrm{x}_{2, \mathrm{j}}+\alpha\left(\mathrm{w}_{3, \mathrm{j}, \mathrm{k}}^{(\mathrm{m})}-\mathrm{w}_{3, \mathrm{j}, \mathrm{k}}^{(\mathrm{m}+\mathrm{l})}\right) \\
& \mathrm{w}_{2, \mathrm{j}, \mathrm{k}}^{(\mathrm{m}+\mathrm{l})}+\eta \delta_{2, \mathrm{k}} \mathrm{x} 2, \mathrm{j}+\alpha\left(\mathrm{w}_{2, \mathrm{j}, \mathrm{k}}^{(\mathrm{m})}-\mathrm{w}_{2, \mathrm{j}, \mathrm{k}}^{(\mathrm{m}+\mathrm{l})}\right.
\end{aligned}
$$

Where $n$ is training speed and $\alpha$ is inertia coefficient. Also, $\mathrm{W}^{(\mathrm{M})}$ shows that weights were calibrated $M$ times. The inertia coefficient was used to avoid problems resulting from the occurrence of local minima and acceleration of convergence. Most neural network studies conducted on hydrology issues use a type of propagation algorithm. To simulate the fluoride concentrations in groundwater in the surrounding villages of Khaf, the single layer perceptron network with a back propagation algorithm was implemented in MATLAB R2014a software, Neural Network. To determine the optimal network architecture, the trial and error method was implemented using diverse network tests with the lowest error rate and the highest correlation coefficient.

\section{Data categorization}

In this study, $70 \%$ of the data was selected for model training, $10 \%$ for validation, and $20 \%$ for model testing. Training procedures (including weights) change over time between different levels; training was conducted as though the difference between actual data (for training data) and predicted data was minimized.

\section{Input data}

To predict fluoride concentrations with a multilayer perceptron (MLP) ANN based on the physical and chemical parameters of water, three models were considered. In the first, second, and third models, there were 5,6 , and 13 variables, respectively. In these models, fluoride concentration was the target element. Table 1 shows the entry information of these models.

\section{Analysis}

To compare the physical properties of the predicted values with the laboratory measurements and the accuracy of the available models, the parameters of coefficient of determination $\left(\mathrm{R}^{2}\right)$ and root mean square error (RMSE) were applied (Equations 9 and 10).

$$
\begin{aligned}
& R^{2}=1-\frac{\sum_{i=1}^{N}(Z-\hat{Z})}{\sum_{i=1}^{N}\left(Z-Z^{*}\right)^{2}} \\
& R S M E=\sqrt{\frac{1}{N}} \sum_{i=1}^{N}\left(Z-Z^{*}\right)^{2}
\end{aligned}
$$

where $Z$ is the predicted values in the $\mathrm{i}^{\text {th }}$ point, $Z^{*}$ is the mean predicted value for properties, $Z$ is observed values for the $\mathrm{i}^{\text {th }}$ point, and $N$ is the number of studied samples. The data was analyzed using Excel software.

\section{Results}

To predict fluoride concentrations by MLP ANN based on the physical and chemical parameters of water, three 
models were considered. In the first model $\left(\mathrm{MLP}_{1}\right), 5$ inputs ( $\mathrm{pH}$, Tem, EC, TDS, and TH) were defined. In the second model $\left(\mathrm{MLP}_{2}\right), 6$ inputs including anions and cations in water $\left(\mathrm{Cl}, \mathrm{SO}_{4}^{-2}, \mathrm{HCO}_{3}^{-}, \mathrm{Ca}^{+2}, \mathrm{Mg}^{+2}, \mathrm{Na}\right)$ were measured. In the third model $\left(\mathrm{MLP}_{3}\right)$, all variables measured in the water were defined $(\mathrm{pH}$, Tem, EC, TDS, TH, Ca. H, Alkalinity, $\left.\mathrm{Cl}, \mathrm{SO}_{4}^{-2}, \mathrm{HCO}_{3}^{-}, \mathrm{Ca}^{+2}, \mathrm{Mg}^{+2}, \mathrm{Na}\right)$. Fluoride concentration was the target element in all three models. During the training process of the models, the most appropriate number of neurons was in the hidden layer, and the most useful function for increasing the accuracy of the learning process was selected from the hidden layer neurons using the trial and error method. Table 2 to Table 4 give information about the model, and modeling results are demonstrated in Table 5. To teach data in the training phase (train), the Levenberg-Marquardt (LM) algorithm was used. The results of structures designed in the MLP neural network architecture indicated that the most appropriate functions used in the hidden layer were triangle (Tribas) and hyperbolic tangent (Tansig) types. The linear function (Purelin) was applied in the output layer.

According to Table 4, the MLP neural network with its low values for RMSE and high values for coefficient of determination for modeling and predicting fluoride in $\mathrm{MLP}_{1}$, performed better than the other two models. As shown in Figure 4, the modeling implemented by the MLP neural network predicted data that had high conformity with the laboratory measured data, which indicates that the implemented modeling could properly estimate fluoride content using different intended inputs.

As seen in Table 6, the lowest fluoride concentration of $0.15 \mathrm{mg} \mathrm{L}^{-1}$ was found in Saddeh village, and the highest concentration of $3.59 \mathrm{mg} \mathrm{L}^{-1}$ was found in Mahabad village. Based on WHO standards, $56.6 \%$ of villages are in the desirable range, $33.3 \%$ of them had fluoride concentrations lower than standard levels, and $10 \%$ had fluoride levels higher than standard. Maximum $\mathrm{pH}$ was

Table 1. Description of models used for $\mathrm{Zn}$ fractions modeling

\begin{tabular}{|c|c|c|c|c|c|c|}
\hline \multirow{2}{*}{ Model } & \multirow{2}{*}{ Inputs } & \multirow{2}{*}{ Output } & \multicolumn{4}{|c|}{ MLP structure } \\
\hline & & & Neuron in hidden layer & HLTF* & OLTF* & Description \\
\hline $\mathrm{MLP}_{1}$ & $\mathrm{pH}, \mathrm{Tem}, \mathrm{EC}, \mathrm{TDS}, \mathrm{TH}$ & $\mathrm{F}^{-}$ & 4 & Tribas & Purelin & LM algorithm** \\
\hline $\mathrm{MLP}_{2}$ & $\mathrm{Cl}, \mathrm{SO}_{4}^{-2}, \mathrm{HCO}_{3}^{-}, \mathrm{Ca}^{+2}, \mathrm{Mg}^{+2}, \mathrm{Na}$ & $\mathrm{F}^{-}$ & 4 & Tansig & Purelin & LM algorithm \\
\hline $\mathrm{MLP}_{3}$ & $\mathrm{pH}, \mathrm{Tem}, \mathrm{EC}, \mathrm{TDS}, \mathrm{TH}, \mathrm{Ca} . \mathrm{H}, \mathrm{Alka}, \mathrm{Cl}, \mathrm{SO}_{4}^{-2}, \mathrm{HCO}_{3}{ }^{-}, \mathrm{Ca}^{+2}, \mathrm{Mg}^{+2}, \mathrm{Na}$ & $\mathrm{F}^{-}$ & 7 & Tribas & Purelin & LM algorithm \\
\hline
\end{tabular}

Table 2. Input data statistics in training and testing stages used for modeling and predicting fluoride $\left(\mathrm{MLP}_{1}\right)$

\begin{tabular}{|c|c|c|c|c|c|c|c|c|}
\hline Model & Level & Des. & $\mathrm{pH}$ & TH & TDS & EC & Turbidity & Temperature \\
\hline \multirow{6}{*}{ MLP1 } & & Max & 8.31 & 748 & 6550 & 4037 & 141.2 & 24.5 \\
\hline & Train & Min. & 7.2 & 53 & 287.17 & 391 & 0.25 & 12.8 \\
\hline & & Mean & 7.95 & 220.41 & 1365.50 & 1531.67 & 7.16 & 21.99 \\
\hline & & Max & 8.31 & 748 & 6550 & 4037 & 142 & 24.1 \\
\hline & Test & Min. & 7.61 & 55 & 287.17 & 391 & 0.24 & 22.6 \\
\hline & & Mean & 7.99 & 224.62 & 1383.97 & 1492.66 & 15.04 & 23.08 \\
\hline
\end{tabular}

Table 3. Input data statistics in training and testing stages used for modeling and predicting fluoride $\left(\mathrm{MLP}_{2}\right)$

\begin{tabular}{|c|c|c|c|c|c|c|c|c|}
\hline Model & Level & Des. & $\mathrm{Na}$ & $\mathrm{Mg}^{+2}$ & $\mathrm{Ca}^{+2}$ & $\mathrm{HCO}_{3}^{-}$ & $\mathrm{SO}_{4}^{-2}$ & $\mathrm{Cl}^{-}$ \\
\hline & & Max & 1162.5 & 66.7 & 188.63 & 375.5 & 942.08 & 1543 \\
\hline & Train & Min. & 10.2 & 3 & 14 & 148.86 & 36.11 & 11.57 \\
\hline \multirow[t]{4}{*}{ MLP2 } & & Mean & 293.78 & 21.64 & 48.29 & 221.68 & 297.13 & 241.44 \\
\hline & & Max & 1162.5 & 57.55 & 204.6 & 375.5 & 942.08 & 1543 \\
\hline & Test & Min. & 25.2 & 8.26 & 23.63 & 148.86 & 36.11 & 26.16 \\
\hline & & Mean & 350.29 & 20.18 & 53.09 & 217.10 & 365.42 & 360.25 \\
\hline
\end{tabular}

Table 4. Input data statistics in training and testing stages used for modeling and predicting fluoride levels (MLP ${ }_{3}$ )

\begin{tabular}{|c|c|c|c|c|c|c|c|c|c|c|c|c|c|c|c|c|}
\hline Model & Level & Des. & $\mathrm{Na}$ & $\mathrm{Mg}^{+2}$ & $\mathrm{Ca}^{+2}$ & $\mathrm{HCO}_{3}^{-}$ & $\mathrm{SO}_{4}^{-2}$ & $\mathrm{Cl}^{-}$ & Alka & Ca. H & TH & TDS & EC & Tur & Tem & $\mathrm{pH}$ \\
\hline & & Max & 1162.5 & 66.7 & 204.6 & 375.5 & 942.08 & 1543 & 308 & 511 & 748 & 6550 & 4037 & 140.4 & 24.1 & 8.31 \\
\hline & Train & Min. & 10.2 & 3 & 14 & 148.86 & 36.11 & 11.57 & 122 & 36 & 55 & 287.17 & 391 & 0.24 & 13.8 & 7.3 \\
\hline \multirow[t]{4}{*}{$\mathrm{MLP}_{3}$} & & Mean & 322.81 & 21.62 & 51.01 & 220.97 & 325.65 & 286.32 & 181.02 & 133.62 & 226.47 & 1436.72 & 1581.02 & 9.69 & 22.70 & 7.96 \\
\hline & & Max & 1055 & 66.7 & 188.63 & 358 & 942.08 & 1261 & 294 & 471 & 548 & 5560 & 3930 & 140.4 & 24.1 & 8.31 \\
\hline & Test & Min. & 10.2 & 4.4 & 14 & 165.95 & 70.07 & 11.57 & 136 & 36 & 55 & 449.5 & 453.71 & 0.24 & 22.6 & 6.9 \\
\hline & & Mean & 300.43 & 21.13 & 53.15 & 218.51 & 337.61 & 253.14 & 180.71 & 136.6 & 228.42 & 1340.55 & 1529.71 & 5.88 & 23.12 & 7.98 \\
\hline
\end{tabular}


Table 5. Results of fluoride modeling using the physical and chemical properties of water

\begin{tabular}{lcccccc}
\hline \multirow{2}{*}{ Models } & \multicolumn{2}{c}{ Train } & \multicolumn{2}{c}{ Validation } & \multicolumn{2}{c}{ Test } \\
\cline { 2 - 7 } & RMSE & $\mathbf{R}^{\mathbf{2}}$ & RMSE & $\mathbf{R}^{\mathbf{2}}$ & RMSE & $\mathbf{R}^{\mathbf{2}}$ \\
\hline $\mathrm{MLP}_{1}$ & 0.11 & 0.98 & 0.11 & 0.94 & 0.23 & 0.93 \\
$\mathrm{MLP}_{2}$ & 0.17 & 0.88 & 0.20 & 0.96 & 0.25 & 0.82 \\
$\mathrm{MLP}_{3}$ & 0.19 & 0.88 & 0.21 & 0.86 & 0.26 & 0.79 \\
\hline
\end{tabular}

related to Shahrak village with 8.31 , and minimum $\mathrm{pH}$ was related to Mahabad village with 7.42. All samples were in normal condition and had a tendency for alkalinity, which made the water unsuitable for drinking. The results also showed that the highest concentration of nitrate ion $\left(83 \mathrm{mg} \mathrm{L}^{-1}\right)$ was found in Ebrahimi vllage, and the lowest concentration $\left(1.54 \mathrm{mg} \mathrm{L}^{-1}\right)$ was found in Shahrak village. Moreover, the highest concentrations of sulfate and chloride ions were related to Mahabad and Bonyabad villages with 942 and $1543 \mathrm{mg} \mathrm{L}^{-1}$, respectively, and the lowest concentrations were related to Ahmadabad and Shahrak villages, both of which measured $36 \mathrm{mg} \mathrm{L}^{-1}$.

\section{Discussion}

ANN was used to predict fluoride concentrations. Three prediction models were applied using various input variables. Previous research has shown that neural network performance changes according to its structure as well as the nature under study. By selecting the appropriate type, number of inputs, a proper and adaptable type of ANN, a proper and efficient technique was established for estimating the fluoride concentrations in groundwater resources in Khaf and surrounding villages. The current study achieved the application of ANN with a multilayer perception structure based on the LM algorithm and propagation method. The findings indicated the neural network's acceptable ability to simulate fluoride in groundwater resources. Based on the results of network performance, the best model was found to be $\mathrm{MLP}_{1}$. Of the three recommended models, MLP $_{1}$ exhibited the most proper structure, and its inputs included $\mathrm{pH}, \mathrm{Tem}$, EC, TDS, and TH. Although it has been said that neural network performance is improved by increasing the

Table 6. Physical and chemical parameters of drinking water reservoirs under study in villages surrounding Khaf city in 2009-2010

\begin{tabular}{|c|c|c|c|c|c|c|c|c|c|c|c|c|c|c|c|c|}
\hline Code & Name of village & $\mathrm{pH}$ & Alkha & Tur. & EC & TDS & TH & Ca. $\mathrm{H}$ & $\mathrm{NO}_{3}^{-}$ & $\mathrm{NO}_{2}$ & $\mathrm{SO}^{-2}$ & $\mathrm{Cl}^{-}$ & $\mathrm{F}^{-}$ & $\mathrm{Ca}^{+2}$ & $\mathbf{M g}^{+2}$ & $\mathrm{Na}^{+}$ \\
\hline 1 & Mahabad & 8.2 & 190 & 0.71 & 2070 & 1336 & 105 & 59 & 19.3 & 0.01 & 500 & 170 & 1.26 & 24 & 11 & 392 \\
\hline 2 & Seidabad & 8 & 147 & 0.94 & 484 & 572 & 105 & 67 & 9.7 & 0.01 & 117 & 86 & 0.98 & 27 & 9 & 149 \\
\hline 3 & Chamanabad & 7.8 & 188 & 0.33 & 944 & 661 & 317 & 178 & 9.9 & 0.01 & 166 & 78 & 0.75 & 71 & 34 & 77 \\
\hline 4 & KHalilabad & 8 & 151 & 0.48 & 765 & 525 & 208 & 113 & 5.45 & 0.01 & 123 & 66 & 0.31 & 45 & 23 & 80 \\
\hline 5 & Hasanabad & 8 & 151 & 0.26 & 918 & 620 & 216 & 121 & 3.86 & 0.01 & 166 & 78 & 0.38 & 49 & 23 & 117 \\
\hline 6 & Ahmadabad & 8 & 122 & 2.24 & 391 & 287 & 141 & 83 & 9.1 & 0.01 & 36 & 26 & 0.17 & 33 & 14 & 25 \\
\hline 7 & Aliabad & 8.2 & 155 & 0.24 & 622 & 449 & 97 & 53 & 3086 & 0.01 & 85 & 41 & 0.44 & 21 & 11 & 100 \\
\hline 8 & Mahabad & 8 & 190 & 0.49 & 1405 & 991 & 97 & 63 & 15.6 & 0.01 & 333 & 114 & 0.63 & 25 & 8.2 & 269.2 \\
\hline 9 & Sarab & 7.9 & 147 & 40.4 & 693 & 693 & 240 & 139 & 2.78 & 0.07 & 157 & 39 & 0.49 & 56 & 24.5 & 54 \\
\hline 10 & KHargerd & 8 & 194 & 0.25 & 138 & 514 & 198 & 93 & 11.8 & 0.01 & 216 & 192 & 0.71 & 37 & 25.5 & 217 \\
\hline 11 & Biasadabad & 8.1 & 151 & 0.92 & 1266 & 931 & 157 & 75 & 14.3 & 0.02 & 164 & 194 & 0.85 & 30 & 15 & 212 \\
\hline 12 & Baghebakhshi & 8 & 160 & 0.62 & 1375 & 807 & 103 & 67 & 40.9 & 0.02 & 256 & 151 & & 27 & 8.7 & 256 \\
\hline 13 & Kalshor & 8.1 & 294 & 2.5 & 2260 & 906 & 186 & 111 & 33.2 & 0.01 & 394 & 283 & 0.93 & 45 & 18.2 & 406 \\
\hline 14 & Zozon & 7.9 & 212 & 41.8 & 3930 & 1517 & 345 & 261 & 67.7 & 0.39 & 594 & 756 & 1.1 & 104 & 20.2 & 682 \\
\hline 15 & Tizab & 7.5 & 147 & 1.94 & 3040 & 2434 & 523 & 248 & 19.8 & 0.01 & 740 & 398 & 0.98 & 99 & 66 & 499 \\
\hline 16 & Faindar & 7.9 & 181 & 0.33 & 736 & 549 & 210 & 91 & 7.3 & 0.02 & 145 & 34 & 0.44 & 36.5 & 28.9 & 79.6 \\
\hline 17 & CHahe gaji & 8 & 203 & 0.5 & 1037 & 696 & 55 & 36 & 22.5 & 0.02 & 131 & 22 & 0.76 & 14 & 4.4 & 206 \\
\hline 18 & Berabad & 8 & 173 & 0.5 & 1675 & 1063 & 188 & 91 & 11.2 & 0.02 & 246 & 268 & 0.89 & 36 & 23 & 271 \\
\hline 19 & Ebrahimi & 8 & 162 & 1 & 3010 & 1904 & 135 & 95 & 83 & 0.02 & 599 & 446 & 1.68 & 38 & 9.7 & 590 \\
\hline 20 & Mehrabad & 7.4 & 198 & 7.25 & 680 & 1019 & 152 & 72 & 8.93 & 0.32 & 102 & 128 & 0.56 & 28 & 19.43 & 155.1 \\
\hline 21 & Shahrak & 8.3 & 221 & 0.45 & 454 & 584 & 283 & 139 & 1.54 & 0.02 & 70 & 11 & 0.32 & 55 & 34.97 & 10 \\
\hline 22 & Sijavand & 7.8 & 202 & 0.3 & 287 & 834 & 281 & 166 & 8.45 & 0.05 & 112 & 54 & 0.9 & 66 & 27.93 & \\
\hline 23 & KHeirabad & 8.21 & 210 & 0.87 & 579 & 783 & 337 & 182 & 4.22 & 0.01 & 149 & 19 & 1 & 72 & 37.6 & 40 \\
\hline 24 & Saddeh & 8 & 163 & 0.35 & 471 & 663 & 202 & 119 & 4.99 & 0.01 & 85.96 & 49 & 0.15 & 47 & 20 & 67 \\
\hline 25 & Bandivan & 8.04 & 223 & 0.34 & 472 & 599 & 249 & 121 & 2.11 & 0.01 & 71.4 & 13 & 0.53 & 48 & 31.8 & 30 \\
\hline 26 & GHaleno & 8.3 & 175 & 0.52 & 476 & 1134 & 218 & 123 & 12.5 & 0.01 & 179.5 & 122 & 0.75 & 49 & 23.7 & 172 \\
\hline 27 & Mojanabad & 8.3 & 175 & 0.47 & 2180 & 3590 & 194 & 99 & 1.82 & 0.01 & 456 & 730 & 1.48 & 39 & 23.7 & 711 \\
\hline 28 & Hasanabad & 8.2 & 308 & 0.34 & 1694 & 2600 & 98 & 59 & 28.3 & 0.01 & 232 & 377 & 1.64 & 23.6 & 9.47 & 566 \\
\hline 29 & Mahabad & 8.23 & 190 & 0.35 & 2242 & 3440 & 123 & 79 & 25.9 & 0.01 & 942 & 311 & 3.59 & 31.6 & 10.68 & 703 \\
\hline 30 & Dehekhatib & 8.2 & 136 & 0.42 & 1142 & 762 & 162 & 78 & 11.7 & 0.02 & 153 & 101 & 0.38 & 34.8 & 18.21 & 190 \\
\hline
\end{tabular}



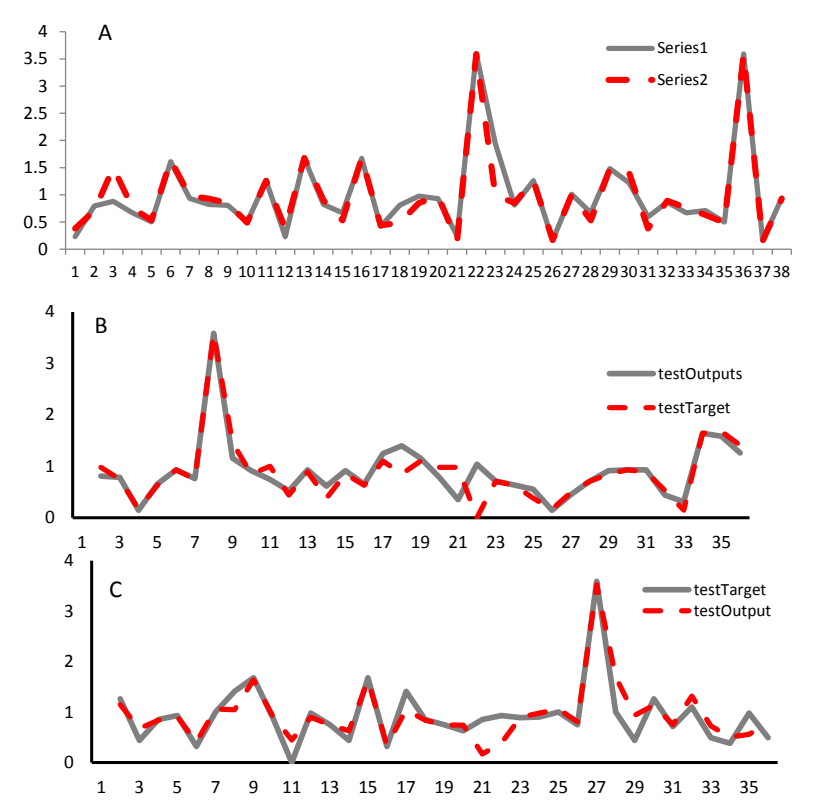

Figure 4. Comparative measured and predicted diagrams for fluoride modeling using certain physical and chemical properties in testing stage: A. MLP 1 , B. MLP ${ }_{2}$, and C. MLP 3 .

number of parameters (26), performance largely depends on the correlation between the variables; fewer inputs resulted in better results in this study, and that represents a savings in time and costs. The LM learning function used the model for necessary predictions in this model, because previous studies had indicated that the LM model exhibits higher learning speed and reduced error. Samani et al highlighted the efficiency of a neural network with the LM algorithm in predicting and simulating parameters of groundwater resources (27).

Asghari Moghadam et al applied ANN models as nonlinear models. Different model structures were evaluated, and FNN-BFG was identified as the best structure for spatial prediction of fluoride concentrations in the region. The findings also showed that fluoride concentrations in the water reservoirs of Bazargan and Pelkdahst plains were higher than the WHO standard. To compare the results of the aforesaid structure with geostatistical methods, two kriging and co-kriging methods were also applied. The $\mathrm{R}^{2}$ values of 0.7285 and 0.8556 were selected for the testing stage. From the three studied models, the most accurate estimate of fluoride concentration was obtained by ANN with the selected model (28). Dar et al predicted fluoride concentrations using an MLP algorithm in which they developed five models with 8 parameters. They considered various inputs for each model. Ultimately, their best model had $\mathrm{pH}$, chloride, sulfate, and calcium inputs, but their results are inconsistent with those of the present paper. It may be concluded that different local conditions in each region cause differing results, because neural network models make better predictions for parameters with the highest relations (29). A study by Nemati et al implemented ANN modeling in TDS concentrations in the Simineh river, Iran. In that study, they evaluated the current water quality and predicted future conditions of this river using ANN model performance based on RMSE, mean absolute error (MAE), and $\mathrm{R}^{2}$. They found that ANNs are made in different numbers of neural cells in hidden layers. A model with 14 hidden layers was selected as the best one. The comparison of measured and predicted values showed that the ANN model could be used with a high level of success, precision, and reliability to determine and predicted water quality (30). Derakhshan et al conducted a study to simulate underground water salinity using the LM algorithm and method of propagation on Mazandaran beaches. The findings showed that, in the best network structure, the $\mathrm{R}^{2}$ between simulated and actual values was equal to 0.75 . Moreover, the factors of surface water salinity, aquifer organization transmissivity (texture and structure), and distance from the sea are the most proper inputs for simulating underground water salinity and were also the main causes of it on Mazandaran beaches. Finally, the researchers indicated that among all algorithms, LM algorithm showed the best efficiency in predicting water salinity (14). A study by Krishna et al examined the efficiency of a neural network with the LM algorithm and propagation method in estimating and forecasting qualitative and quantitative parameters of groundwater (31). Mirzavand et al predicted levels of underground water using ANN in which the LM algorithm and hyperbolic tangent function rendered the best results among the studied models (30). Cordoba et al predicted the chlorine concentration in WDS using statistical models based on ANN in combination with Monte-Carlo. The model was tested on one specific location using hydraulic and water quality parameters such as flow, $\mathrm{pH}$, temperature, and others. The ANN model was used with significant success and reliability to determine and predict water quality (32). A study by Sarkar et al implemented ANN modeling in an investigation of DO concentrations in stream water quality. The predicted values of DO showed prominent accuracy by producing high correlations (up to 0.9) between the measured and predicted values (33). Seo et al predicted water quality parameters (temperature, $\mathrm{DO}, \mathrm{pH}$, electric conductivity, TN, TP, turbidity, and chlorophyll-a) downstream of the Cheongpyeong Dam using ANN. Seven parameters (temperature, $\mathrm{DO}, \mathrm{pH}$, electric conductivity, TN, TP, and chlorophyll-a) all had values higher than 0.85 $\mathrm{R}^{2}$, and 5 parameters (temperature, $\mathrm{DO}, \mathrm{pH}, \mathrm{TN}$, and $\mathrm{TP}$ ) showed lower than 1.0 RMSE (34).

\section{Conclusion}

The present study aimed to predict and model fluoride concentrations in underground water resources in Khaf city and surrounding villages using ANN software. Fourteen water features were measured as inputs and categorized in three models. Among the three models implemented by the software, model 1 , designed with the LM algorithm based on the propagation system, provided the best results calculating a RMSE of 0.23 and a correlation coefficient equal to 0.93 . Simulation results in the testing stage for $\mathrm{MLP}_{1}$ as well as the high conformity 
between experimental and predicted data indicate that this model with its high confidence coefficient can be used to predict fluoride concentrations.

\section{Acknowledgments}

This work was supported by Students Research Committee, Neyshabur University of Medical Sciences, Neyshabur, Iran (grant No. 57).

\section{Competing interests}

The authors of this article declare that they have no competing interests.

\section{Ethical issues}

The authors of this article confirm that this article is their original work. It has not been published, nor is it under review in another journal, and it is not being submitted for publication elsewhere.

\section{Authors' contributions}

All authors contributed equally and were involved in the study design, data collection, and article approval.

\section{Reference}

1. Affadi AK, Watanabe K, Tirtomihardjo H. Application of an artificial neural network to estimate groundwater level fluctuation. Journal of Spatial Hydrology 2007; 7(2): 23-46.

2. Massoudinejad M, Ghaderpoori M, Shahsavani A, Amini MM. Adsorption of fluoride over a metal organic framework Uio-66 functionalized with amine groups and optimization with response surface methodology. J Mol Liq 2016; 221: 279-86. doi: 10.1016/j.molliq.2016.05.087.

3. Amouei AI, Mahvi AH, Mohammadi AA, Asgharnia HA, Fallah SH, Khafajeh AA. Fluoride concentration in potable groundwater in rural areas of Khaf city, Razavi Khorasan province, Northeastern Iran. Int J Occup Environ Med 2012; 3(4): 201-3.

4. Guidelines for Drinking Water Quality, Criteria and Other Supportion Information (volume 2). Geneva: WHO; 1984.

5. Faraji H, Mohammadi AA, Akbari-Adergani B, Vakili Saatloo N, Lashkarboloki G, Mahvi AH. Correlation between fluoride in drinking Water and its levels in breast milk in Golestan Province, Northern Iran. Iran J Public Health 2014; 43(12): 1664-8.

6. Ghaderpoori M, Jahed Khaniki GR, Dehghani MH, Shams M, Zarei A. Determination of Fluoride in Bottled Water Sold in Tehran Market, Iran. Am Eurasian J Agri Environ Sci 2009; 6(3): 324-7.

7. Cairncross S, Feachem RG. Environmental Health Engineering in the Tropics: An Introductory Text. Trans by Eysalo M, Mahvi AH. London: Wiley; 1992.

8. Fallahian F. Fluorosis. Journal of Dental Medicine 2003; 16(2): 73-78. [In Persian].

9. Oude Essink GH. Improving fresh groundwater SupplyProblems and solutions center of hydrology. Ocean Coast Manag 2001; 44(5-6): 429-49.

10. Chen JC, Chang NB, Shieh WK. Assessing wastewater reclamation potential by neural network model. Eng Appl Artif Intell 2003; 16(2): 149-57. doi: 10.1016/S09521976(03)00056-3.

11. Lallahem S, Mania J, Hani A, Najjar Y. On the use of neural networks to evaluate groundwater levels in fracturedmedia. J Hydrol 2005; 307(1-4): 92-111. doi: 10.1016/j. jhydrol.2004.10.005.

12. Bijari MK, Golkar Hamzee Yazd HR, Tavousi M. Evaluation of artificial neural network models and time series in the estimation of hydrostatic level (case study: South Khorasan province-Birjand aquifer). J Mater Environ Sci 2015; 6(12): 3539-47.

13. Kuo YM, Liu CW, Lin KH. Evaluation of the abilit y of an artificial neural network model to assess the variation of groundwater quality in an area of black foot disease in Taiwan. Water Res 2004; 38(1): 148-58. doi: 10.1016/j. watres.2003.09.026.

14. Derakhshan SH, Gholami V, Darvari Z. Simulation of ground water salinity by using artificial neural network (ANN) on the Mazandaran province coasts. Journal of Irrigation Science and Engineering. 2013; 36(2): 61-70. [In Persian].

15. Jain AK, Mao J, Mohiuddin KM. Artificial neural networks: a tutorial. Computer, IEEE 1996; 31-44.

16. Gaur S, Ch S, Graillot D, Chahar BR, Kumar DN. Application of artificial neural networks and particle swarm optimization for the management of groundwater resources. Water Resources Management 2013; 27(3): 92741. doi: 10.1007/s11269-012-0226-7.

17. Alborzi M. Introduction to Neural Networks. 1st ed. Tehran: Sharif University of Technology; 2001. [In Persian].

18. Hore A, Dutta S, Datta S, Bhattacharjee C. Application of an artificial neural network in wastewater quality monitoring: prediction of water quality index. International Journal of Nuclear Desalination 2008; 3(2): 160-74. doi: 10.1504/ IJND.2008.020223.

19. Huiqun, Ma, and Liu Ling. "Water quality assessment using artificial neural network." In Computer Science and Software Engineering, 2008 International Conference on, vol. 1, pp. 13-15. IEEE, 2008.

20. Kunwar P, Singh A, Amrita M, Gunja J. Artificial neural network modeling of the river water quality-a case study. Ecol Modell 2009; 220(6): 888-95. doi: 10.1016/j. ecolmodel.2009.01.004.

21. Sandhu N, Finch R. Artificial Neural Networks and Their Applications. In: Methodology for Flow and Salinity Estimates in the Sacramento-San Joaquin Delta and Suisun Marsh. New York; 1995. p. 85-6.

22. Walley WJ, Fontana VN. Neural network prediction of average scope per taxon and number of families at unpolluted river sites in Great Britain. Water Rersources Research 1998; 32: 613-22.

23. Rahimzadeh H, Kargar M, Dadban Y, Birami S. Fluoride level in drinking water resources of Gorgan rural regions. Med Lab J 2007; 1(2): 45-9. [In Persian].

24. Eaton A. Standard Methods for the Examination of Water Waster. 21th ed. Washington DC: American Water Works Associations; 2005.

25. Dreyfus G, Martinez JM, Samuelides M, Gordon MB, Badran F, Thiria S. Apprentissage statistique: Réseaux de neurones-Cartes topologiques-Machines à vecteurs supports. Eyrolle; 2011.

26. Khashei Siuki A, Kouchakzadeh M, Ghahraman B. Predicting dryland wheat yield from meteorological data using expert system in Khorasan province. J Agric Sci Tech 2011; 13(4): 627-40.

27. Samani N, Gohari-Moghadam M, Safavi AA. A simple 
neural network model for the determination of aquifer parameters. J Hydrol 2007; 340(1-2): 1-11. doi: 10.1016/j. jhydrol.2007.03.017. doi: 10.1016/j.jhydrol.2007.03.017.

28. Asghari Moghaddam A, Nadiri AA, Fijani E. Spatial prediction of fluoride concentration using artificial neural networks and geostatic models. Water and Soil Science 2009; 19(2): 129-45. [In Persian].

29. Dar IA, Sankar K, Dar MA, Majumder M. Fluoride concentration - artifical neural network modeling and inverse distance weighting approch. J Water Sci 2012; 25(2): 165-182.

30. Nemati S, Naghipour L, Fazeli Fard MH. Artificial neural network modeling of total dissolved solid in the Simineh river, Iran. J Civil Eng Urban 2014; 4(1): 8-13.

31. Krishna B, Satyaji Rao YR, Vijaya T. Modeling roundwater levels in an urban coastal aquifer using artificial neural networks. Hydrol Process 2008; 22(8): 1180-8. doi: 10.1002/ hyp. 6686.

32. Cuesta Cordoba GA, Tuhovčák L, Tauš M. Using Artificial neural network models to assess water quality in water distribution networks. Procedia Eng 2014;70:399-408. doi: 10.1016/j.proeng.2014.02.045.

33. Sarkar A, Pandey P. River water quality modelling using artificial neural network technique. Aquatic Procedia 2015; 4: 1070-7. doi: 10.1016/j.aqpro.2015.02.135.

34. Seo Iw, Yun SH, Choi SY. Forecasting water quality parameters by ANN model using pre-processing technique at the downstream of Cheongpyeong Dam. Procedia Eng 2016; 154: 1110-5. doi: 10.1016/j.proeng.2016.07.519. 